\title{
Aplikasi Cek Nutrisi pada Makanan Berbasis Android
}

\author{
An Android-Based Nutrition Check Application for Food
}

\author{
Maulida Ayu Fitriani ${ }^{*}$, Andono Pamungkas Warih² \\ 1,2Program Studi Teknik Informatika Fakultas Teknik dan Sains, Universitas Muhammadiyah Purwokerto
}

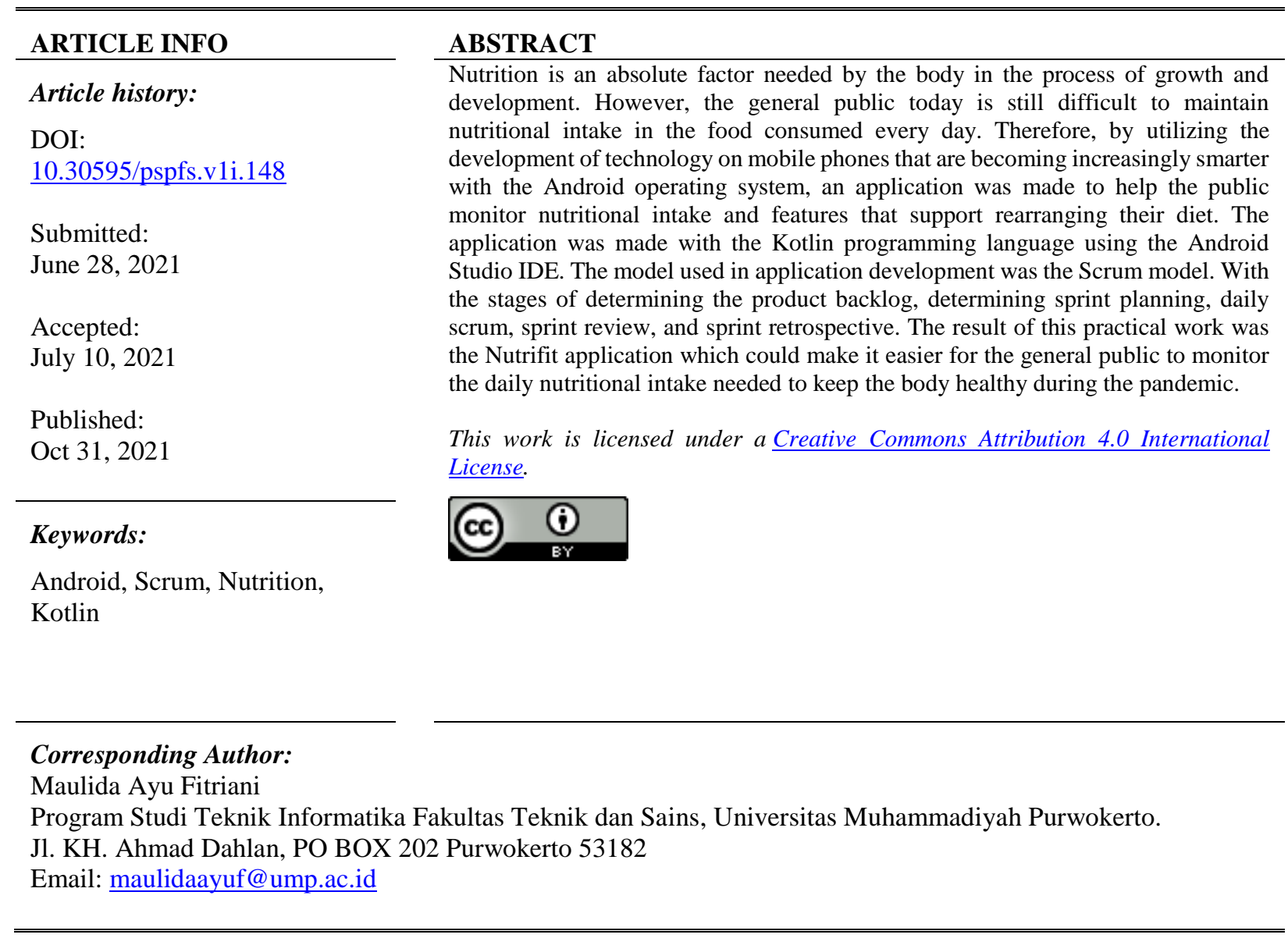

\section{PENDAHULUAN}

Perkembangan handphone pada masa sekarang sudah sangat pesat mobilitas seseorang yang cepat berdampak ke aplikasi dan juga ke perangkat pendukungnya. Perkembangan teknologi pada handphone sudah semakin maju, handphone kini menjadi semakin pintar berkat sistem operasi android. Android adalah sistem operasi yang berbasis Linux untuk telepon seluler seperti telepon pintar dan komputer tablet (Listyorini and Widodo, 2013). Handphone yang menggunakan sistem operasi android disebut juga sebagai smartphone. Smartphone menjadikan mobilitas pengguna akan semakin cepat, karena sifatnya handphone yang mudah dan dapat digunakan dimana saja, sehingga dengan adanya aplikasi didalam sebuah smarphone maka akan sangat membantu aktivitas yang memiliki mobilitas tinggi.

Nutrisi atau gizi merupakan faktor mutlak yang diperlukan oleh tubuh dalam proses tumbuh kembang. Kebutuhan nutrisi untuk setiap orang berbedabeda dipengaruhi oleh usia, jenis kelamin dan aktifitas. Pola makan dan asupan gizi yang tidak tepat merupakan sumber masalah kesehatan.

Data pada tahun 2008 yang dikeluarkan oleh organisasi kesehatan dunia atau World Health Organization (WHO) menunjukkan bahwa obesitas merupakan masalah epidemiologi global yang menjadi ancaman serius bagi kesehatan masyarakat dunia. Lebih dari 1,4 miliar orang dewasa berusia di atas 20 tahun mengalami kelebihan berat badan (Sudargo, Freitag and Aini, 2016).

Masyarakat umum saat ini masih sulit untuk menjaga asupan nutrisi pada makanan yang di konsumsi setiap hari. Aplikasi pemantau asupan nutrisi dengan fitur-fitur pendukung untuk menjaga asupan nutrisi yang dikonsumsi setiap 
hari dapat menjadi solusi. Aplikasi ini digunakan untuk mengatur ulang pola makan, data makanan yang diambil yaitu makanan yang dimakannya setiap harinya, data harian ini bisa disebut juga sebagai rekap harian. Setelah mengetahui total nutrisi yang dimakan setiap harinya pengguna diharapkan dapat mengatur kembali pola makan agar didapatkannya kondisi tubuh yang sehat.

Aplikasi dibuat dengan dengan berbasiskan Android menggunakan bahasa pemrograman Kotlin dan menggunakan API 3. Semua data dan informasi disimpan secara online di server, namun aplikasi hanya menampilkan nutrisi makanan yang di input-kan.

Kotlin adalah sebuah bahasa pemrograman dengan Statically typed (tipe statis) yang berjalan pada Java Virtual Machine ataupun menggunakan Compiler LLVM yang dapat dikompilasikan ke dalam bentuk Source Code JavaScript (Aljundi and Akbar, 2018).

Application programming interface (API) merupakan suatu dokumentasi yang terdiri dari interface, fungsi, kelas, struktur dan sebagainya untuk membangun sebuah perangkat lunak. Dengan adanya API ini, maka memudahkan programmer untuk "membongkar" suatu software, kemudian dapat dikembangkan atau diintegrasikan dengan perangkat lunak yang lain. API dapat dikatakan sebagai penghubung suatu aplikasi dengan aplikasi lainnya yang memungkinkan programmer menggunakan sistem function. Proses ini dikelola melalui sistem operasi (Ramadhani, 2015).

Android Studio merupakan perangkat lunak buatan Google untuk para developer android dalam membuat dan mengembangkan aplikasi android. Android Studio menawarkan banyak fitur yang memungkinkan alur kerja pengembangan Anda menjadi lebih mudah dan menyenangkan dalam satu set (Aziz and Dkk, 2018).

\section{METODE PENELITIAN}

Metode pengembangan yang digunakan adalah sistem Agile Development Method dengan menggunakan model Scrum. Model Scrum merupakan suatu pendekatan interaktif pada pengembangan perangkat lunak yang mengusung prinsip agile, metode Scrum ini memiliki tiga artefak, yaitu product backlog, sprint backlog, dan deliverable (Novri Hadinata, 2017). Gambar 1 merupakan tahapan dan pihak yang terlibat dalam Scrum.

1. Role pada model Scrum terdiri dari 3 role yaitu Scrum Master, Product Owner Product dan Scrum Development Team.

2. Urutan pelaksanaan pada model Scrum yaitu Product Backlog (pengumpulan data), Sprint Planning, Daily Scrum dan Sprint Review.

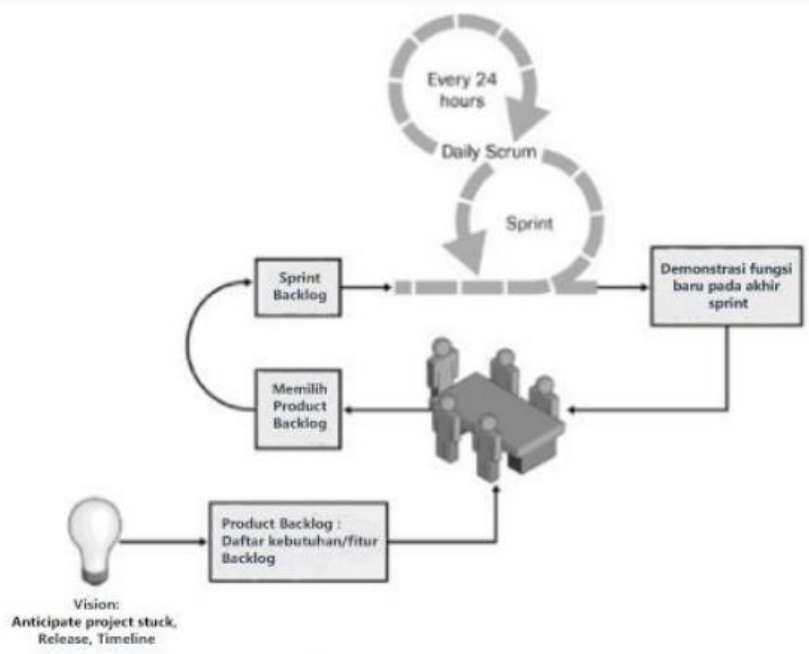

Gambar 1. Tahapan dan pihak yang terlibat dalam scrum (Schwaber, 2004).

\section{HASIL DAN PEMBAHASAN}

\section{Hasil Product Backlog}

User story dibuat dengan menggunakan data yang telah diperoleh. User Story diurutkan berdasarkan pada skala prioritas. Skala prioritas digunakan sebagai acuan fitur-fitur yang menjadi fokus selama pengembangan aplikasi. Tabel 1 merupakan tabel user story. 
Tabel 1. User story

\begin{tabular}{|c|c|c|}
\hline No. & User Story & Prioritas \\
\hline 1 & $\begin{array}{l}\text { Sebagai pengamat nutrisi makanan saya ingin } \\
\text { mengetahui kandungan nutrisi di piring saya. Jadi saya } \\
\text { ingin mensearch makanan saya }\end{array}$ & $10 / 10$ \\
\hline 2 & $\begin{array}{l}\text { Sebagai pengguna yang sedang diet. Saya ingin } \\
\text { mengetahui nutrisi harian saya. Jadi saya ingin list harian } \\
\text { nutrisi saya. }\end{array}$ & $9 / 10$ \\
\hline 3 & $\begin{array}{l}\text { Sebagai orang yang sedang diet saya ingin memiliki } \\
\text { apilikasi untuk merencanakan diet saya. Jadi fitur diet } \\
\text { planing sangatlah perlu }\end{array}$ & $8 / 10$ \\
\hline 4 & $\begin{array}{l}\text { Sebagai pengguna, saya ingin menggunakan apilikasi di } \\
\text { berberapa device. Jadi user account sangatlah perlu }\end{array}$ & $7 / 10$ \\
\hline
\end{tabular}

\section{Hasil Sprint Planning}

User Story yang telah dibuat akan di jabarkan lagi menjadi tugas-tugas kecil yang akan di kerjakan oleh tim developer. Desain yang sudah dibuat pada tahapan Sprint Planning kemudian di implementasikan ke dalam aplikasi. Pada sprint 1 tim developer akan mengerjakan fitur utama yaitu mencari makanan, task yang dikerjakan dapat dilihat pada Tabel 2.

Tabel 2. Sprint 1 fitur search manual.

\begin{tabular}{lllc}
\hline Fitur Backlog & \multicolumn{1}{c}{ Task } & Urutan Sprint \\
\hline Sebagai pengamat & $\bullet$ & Implementasi desain beranda, dialog list, dan & Sprint 1 \\
nutrisi makanan saya & & halaman detail nutrisi makanan dari figma. & \\
ingin mengetahui & $\bullet$ & Implementasi fitur cari makanan manual. & \\
kandungan nutrisi di & $\bullet$ & Implementasi detail nutrisi makanan. & \\
piring saya. Jadi saya & $\bullet$ & Implementasi API Calorie Ninjas. \\
ingin men-search & $\bullet$ & Implementasi Autosave list makanan ke API. & \\
makanan saya. & & & \\
\hline
\end{tabular}

Sprint 2 digunakan untuk fitur melihat list nutrisi harian (History), dapat dilihat pada Tabel 3.

Tabel 3. Sprint 2 implementasi fitur cek nutrisi harian (history).

\begin{tabular}{|c|c|c|}
\hline Fitur Backlog & Task & Urutan Sprint \\
\hline $\begin{array}{l}\text { Sebagai pengguna } \\
\text { yang sedang diet. } \\
\text { saya } \\
\text { mengetahui nutrisi } \\
\text { harian saya. jadi saya } \\
\text { ingin list harian } \\
\text { nutrisi saya. }\end{array}$ & $\begin{array}{l}\text { - Menambahkan desain pada halaman } \\
\text { beranda dan Implementasi halaman history } \\
\text { dari figma. } \\
\text { - Membuat list item history pada halaman } \\
\text { beranda. } \\
\text { - Mengimplementasikan API history. } \\
\text { - Membuat halaman history beserta fungsi di } \\
\text { dalamnya. }\end{array}$ & Sprint 2 \\
\hline
\end{tabular}

Sprint 3 digunakan untuk membuat detail asupan nutrisi harian dapat dilihat pada Tabel 4.

Tabel 4. Sprint 3 Membuat detail asupan nutrisi harian.

\begin{tabular}{|c|c|c|}
\hline Fitur Backlog & Task & Urutan Sprint \\
\hline $\begin{array}{l}\text { Sebagai orang yang } \\
\text { sedang diet saya } \\
\text { ingin memiliki } \\
\text { aplikasi untuk } \\
\text { merencanakan diet } \\
\text { saya. Jadi fitur diet } \\
\text { planning sangatlah } \\
\text { perlu. }\end{array}$ & $\begin{array}{l}\text { - Membuat detail asupan makanan pada } \\
\text { halaman cek nutrisi harian. } \\
\text { - Implementasi fitur diagram. }\end{array}$ & Sprint 3 \\
\hline
\end{tabular}


Sprint 4 digunakan untuk implementasi fitur sign up dengan google email dapat dilihat pada Tabel 5.

Tabel 5. Sprint 4 Implementasi fitur sign up dengan google email.

\begin{tabular}{lllc}
\hline Fitur Backlog & & Task & Urutan Sprint \\
\hline Sebagai pengguna, saya & $\bullet$ & Implementasi desain untuk sign up. & Sprint 4 \\
ingin menggunakan & $\bullet$ & Menyimpan token key untuk akses ke & \\
apilikasi di beberapa & & semua API setelah user berhasil login. & \\
device. Jadi user account & & & \\
sangatlah perlu. & & \\
\hline
\end{tabular}

\section{Desain Sistem}

Use case diagram pada Gambar 2 menjelaskan bahwa pengguna dapat menggunakan beberapa fitur seperti sign up/login, mengelola setting, input makanan, melihat nutrisi makanan, dan melihat history atau nutrisi yang di konsumsi setiap harinya.

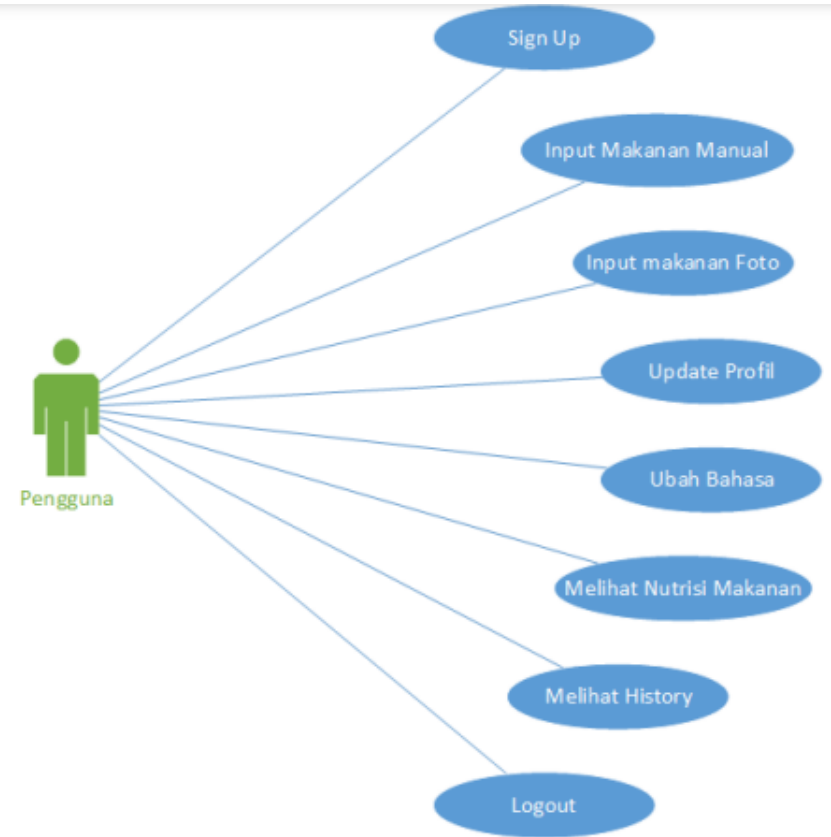

Gambar 2. Use case diagram nutrifit.

\section{Hasil Implentasi Desain}

Gambar 3 merupakan tampilan awal aplikasi, yaitu halaman pendaftaran dan beranda. Pengguna bisa masuk dengan menggunakan akun gmail yang terdaftar pada perangkat smartphone. Gambar 3 merupakan tampilan utama aplikasi yaitu halaman pengecekan kandungan nutrisi pada makanan. 

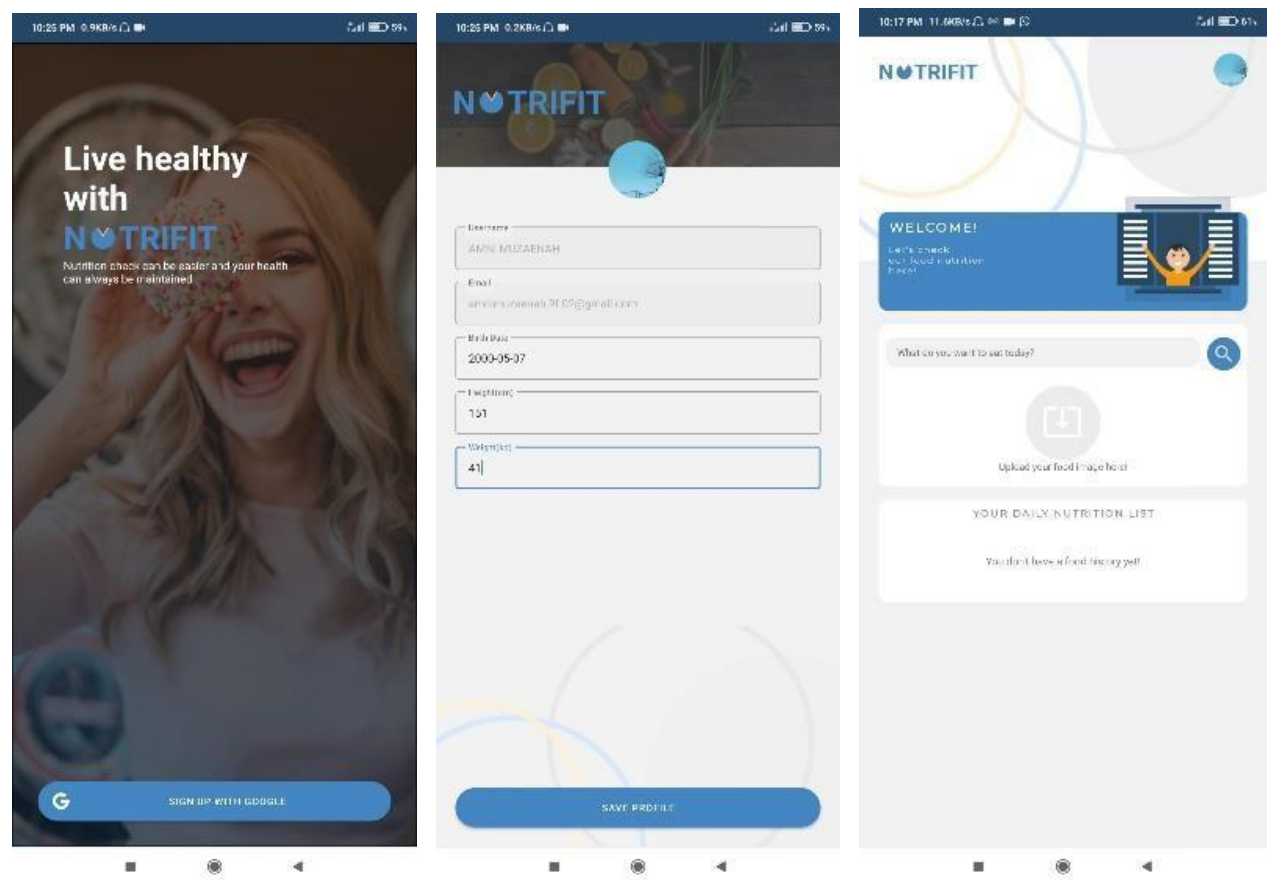

Gambar 3. Tampilan awal aplikasi.
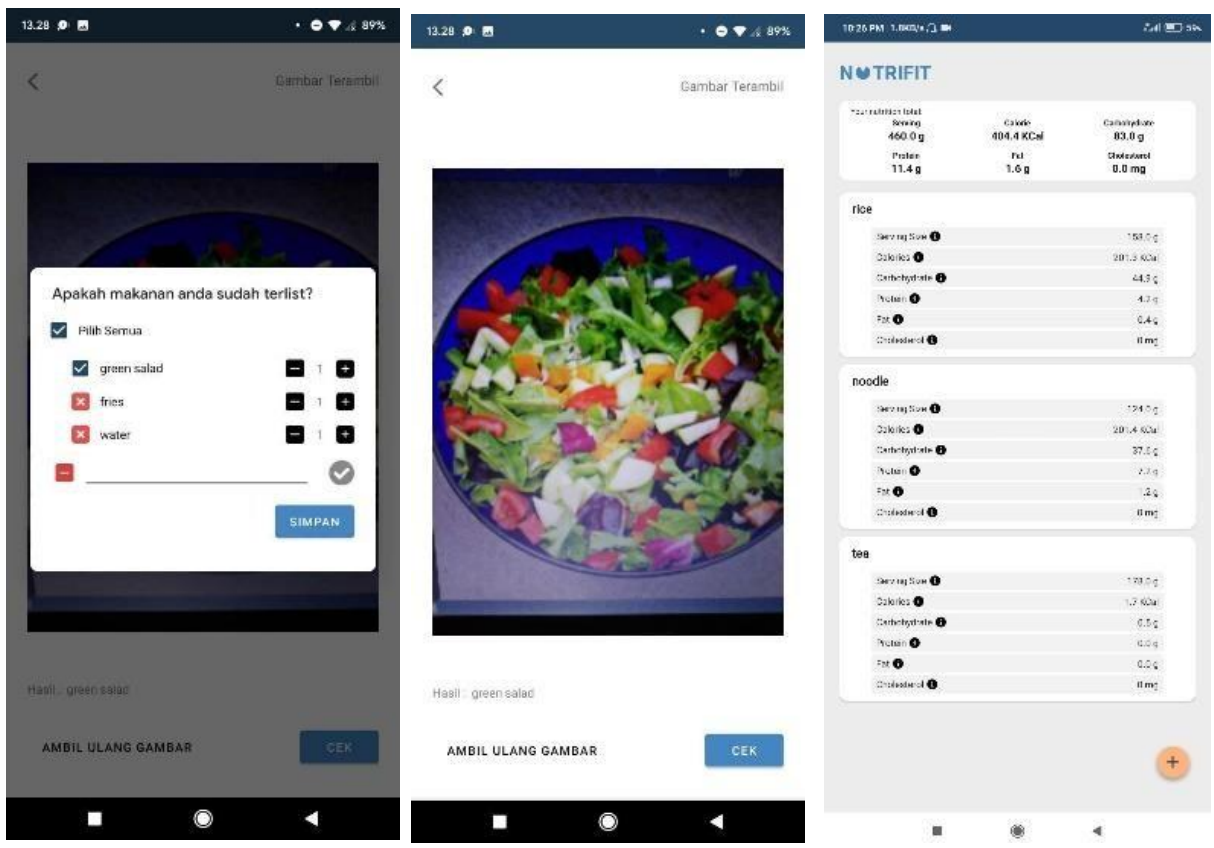

Gambar 4. Pengecekan kandungan nutrisi pada makanan.

\section{Daily Scrum}

Daily Scrum dilakukan setiap hari dalam sebulan setiap sehari sekali setiap 15 menit. Pada waktu tersebut kami membahas pekembangan pada fitur atau kebutuhan, kendala yang terjadi dan apa yang akan dilakukan selanjutnya. Sprint Review

Sprint Review dilakukan setelah 1 kali sprint atau 1 minggu, dan kegiatan ini terjadi selama 2 jam. Dalam waktu tersebut masing-masing anggota/tim akan membahas mengenai output yang dihasilkan selama 1 kali sprint. Perkembangan pada project meliputi sejauh apa sistem, fitur, atau kebutuhan yang dikembangkan, bagian apa saja yang perlu diperbaiki atau diganti.

\section{Sprint Retrospective}

Sprint Retrospective dilakukan setelah 1 kali sprint atau 1 minggu dan dilaksanakan dalam waktu 2 jam. Kegiatan yang dilakukan yaitu mengevaluasi kinerja tim selama proses development berjalan. 


\section{KESIMPULAN}

Berdasarkan hasil dan pembahasan di atas, dapat disimpulkan bahwa aplikasi android untuk membantu memantau nutrisi harian yang dimakan masyarakat berhasil dibangun. Masyarakat dapat dengan mudah dalam mengontrol nutrisi harian yang mereka komsumsi.

\section{DAFTAR PUSTAKA}

Aljundi, M. I. and Akbar, M. A. (2018) Kotlin Zero to Hero: Membuat Aplikasi Android dengan Kotlin cocok untuk Pemula. UDACODING.

Aziz, A. And Dkk (2018) BERMAIN ANDROID STUDIO ITU MUDAH STUDI KASUS PEMBUATAN EMTILANG. Yogyakarta: deepublish.

Listyorini, T. and Widodo, A. (2013) 'Perancangan Mobile Learning Mata Kuliah Sistem Operasi Berbasis Android', Simetris : Jurnal Teknik Mesin, Elektro dan Ilmu Komputer, 3(1), p. 25. doi: 10.24176/simet.v3i1.85.

Novri Hadinata, M. N. (2017) 'Implementasi Metode Scrum Dalam Rancang Bangun Sistem Informasi Penjualan ( Study Kasus: Penjualan Sperpart Kendaraan )', Jurnal Ilmiah Betrik, 08(01), pp. 22-27. Available at: https://ejournal.lppmstipagaralam.ac.id/index.php/betrik/index.

Ramadhani, M. F. (2015) 'Pembangunan Aplikasi Informasi, Pengaduan, Kritik, Dan Saran Seputar Kota Cimahi Pada Platform Android', Jurnal Ilmiah Komputer dan Informatika (KOMPUTA), p. 9.

Sudargo, T., Freitag, H. And Aini, N. (2016) Pola Makan dan Obesitas. Cetakan ke.Yogyakarta: Gadjah Mada University Press.

Schwaber, K. (2004) Agile Project Management With Scrum. United States: Microsoft Press. 